\title{
Comparative Analysis on Influencing Factors of Alignment Monitoring Between Continuous Rigid- frame Bridge and Continuous Girder Bridge
}

\author{
Changfeng Wang \\ School of Civil Engineering, Yantai University, Yantai 264005, China
}

Corresponding Author Email: wangchangfeng1977@ytu.edu.cn

https://doi.org/10.18280/i2m.180412

Received: 15 April 2019

Accepted: 28 June 2019

\section{Keywords:}

continuous rigid-frame $(C R F)$ bridge, continuous girder (CG) bridge, construction sequences, cumulative displacement

\begin{abstract}
In this paper, finite-element models are created for a continuous rigid-frame (CRF) system and a continuous girder (CG) system with the same superstructure. Next, two indices were selected to measure the difficulty of alignment monitoring, namely, the cumulative displacement in cantilevering and the difference between the two sides of the closure gap (the cross-gap difference) in cumulative displacement. After that, the two models were utilized to analyze how design parameters, pre-tensioning sequence and closure sequence affect the alignment monitoring difficulty of the two types of bridges. The analysis shows that the CRF bridge was less affected by prestress force and closure sequence than the CG bridge. This means the pretensioning sequence has greater impacts on the cumulative displacement of the CRF bridge than the CG bridge. The reasons for the impacts were further analyzed, and the closure sequence was rationalized. The research findings shed important new light on the alignment monitoring of CRF bridges.
\end{abstract}

\section{INTRODUCTION}

The continuous rigid-frame (CRF) bridge $[1,2]$ can be casted segmentally using cantilevers, offering a desirable way to span long distances. To cross a wide valley or river, it is necessary to build a multi-span CRF bridge through a complex cantilevering process [3]. The key to the construction of the multi-span CRF bridge lies in the closure segment. In the closure phase [4], the construction sequences mainly include the closure sequence and the pre-tensioning sequence $[5,6]$. The former directly affects the girder alignment and stress of the bridge after closure. Together, the two sequences determine the cumulative displacement and internal force of the finished bridge. Therefore, the alignment of the CRF bridge should be monitored to keep the girders aligned in cantilevering $[7,8]$. In addition, the bridge must be properly precambered to offset the displacement in that phase $[9,10]$.

Most existing studies on bridge monitoring focus on the long term $[11,12]$. Only a few scholars have discussed the deformation monitoring in the construction process $[13,14]$. There is almost no report that compares the alignment monitoring between the CRF bridge and the CG bridge. On the deformation monitoring of bridge construction, the research focus lies in the effects of structural dead weight, prestress, creep and other parameters on girder deformation, rather than the influence of closure process on girder deformation. In fact, the closure process directly affects the structural system under subsequent loads like dead weight and prestress force. These loads cause different degrees of displacement to such systems as cantilever and the CG.

To sum up, many scholars have explored the influence of closure sequence on the deformation and internal force of bridges built using cantilevers. However, most of them only dealt with CG bridge, failing to take account of CRF bridge. To make up for this gap, this paper attempts to compare the factors affecting the alignment monitoring of CG bridge and CRF bridge. Firstly, two indices were selected to measure the difficulty of alignment monitoring, namely, the cumulative displacement in cantilevering and the difference between the two sides of the closure gap (hereinafter referred to as the cross-gap difference) in cumulative displacement. In this way, the research problem is converted to disclosing the effects of the two construction sequences (closure sequence and pretensioning sequence) on the CRF and CG systems. Next, a four-span CRF bridge was selected to analyze how construction sequences affect CRF bridge. From left to right, the four spans are respectively $65 \mathrm{~m}, 112 \mathrm{~m}, 112 \mathrm{~m}$ and $65 \mathrm{~m}$ in length. Finally, the author contrasted CRF bridge with CG bridge, and explored the impacts of construction sequences on the alignment of each type of bridge.

\section{PROJECT OVERVIEW}

According to the construction sequences, the four-span CRF bridge (Figure 1) can be divided into 95 girder segments in 19 categories. The pier segments in each category was assigned a number.

Category 0\# has three $11 \mathrm{~m}$-long girder segments, each of which corresponds to the top of a rigid-frame pier. From Categories $1 \# \sim 5 \#$, each category has six $3 \mathrm{~m}$-long girder segments. From Categories $6 \# \sim 8 \#$, each category has six $3.5 \mathrm{~m}$-long girder segments. From Categories 9\# 14\#, each category has six $4 \mathrm{~m}$-long girder segments. Category $15 \#$ has two $3.0 \mathrm{~m}$ long girder segments, which are super large girder segments built through asymmetric cantilevering over the two side spans. For categories 16 and 16', each category has two $2 \mathrm{~m}$-long closure girder segments. Category $17 \#$ has two $5.8 \mathrm{~m}$ long cast-in-situ girder segments over the two side spans. 
The girder segments of Category $1 \#$ are the heaviest segments built with the movable suspended scaffolding system. Each segment is about 180t in weight. Over the side spans, the largest girder segments belong to Category 15\#. Over the midspans, the largest girder segments belong to Category $14 \#$.

The bridge was constructed through cantilevering using a movable suspended scaffolding system. Since a side pier is taller than the other side pier, the closure sequence was designed as: cantilevering to the girder segments of Category $14 \# \rightarrow$ midspan closure $\rightarrow$ cantilevering to the girder segments of Category $15 \# \rightarrow$ side span closure.

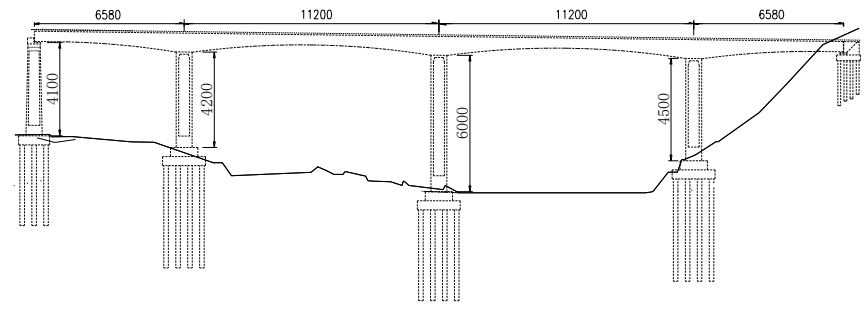

Figure 1. Structure of the four-span CRF bridge

\section{FINITE-ELEMENT MODELS}

The four-span CRF bridge was modelled on Doctor Bridge software. According to the design drawing, a finite-element model (Figure 2(a)) was established to reflect the construction load on the entire bridge. Firstly, the bridge was subjected to forward analysis, revealing the deformations states of the main girder in different phases. Next, 168 nodes (grid points) were identified based on the girder segments of cantilevering, pivot points, midspans, etc. Thus, the bridge was meshed into a total of 167 grids.

To disclose the effects of pre-tensioning sequence on CRF bridge and CG bridge, a CG bridge model [15] was set up with the same structural dimensions, prestressed steel cables and construction procedures as the superstructure of the four-span CRF bridge. As shown in Figure 2(b), the CG bridge model include 131 nodes and 130 grids.

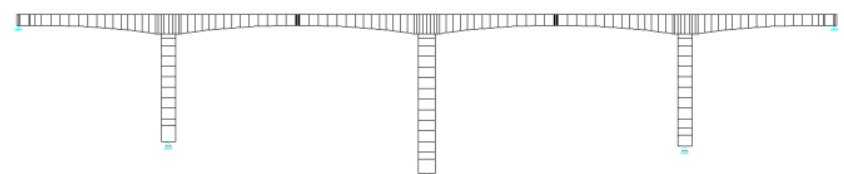

(a)Finite-element model of the CRF system

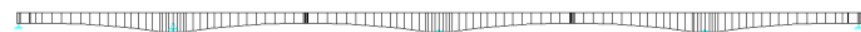

(b)Finite-element model of the CG system

Figure 2. Finite-element models

\section{PARAMETER SENSITIVITY ANALYSIS}

During the alignment monitoring in the cantilevering phase, the cumulative displacement of the finished bridge and the precamber in the construction process could be affected by many design parameters, namely, elastic modulus of materials, bulk density of materials, shrinkage and creep of concrete and the prestress force. The changes of these parameters lead to deviation between actual and theoretical deformations of the bridge, affecting the pre-camber setting.

In this paper, each design parameter is increased and reduced by $10 \%$ to evaluate how much the parameter affects the alignment monitoring. For the lack of space, the author only analyzed the parameters with $10 \%$ float. Next, the sensitivities of the CRF system and the CG system to the variation in each design parameter were analyzed under the construction sequences in the original design, aiming to disclose how much each design parameter affects the two types of bridges. The results of parameter sensitivity analysis are presented in Figure 3 below.

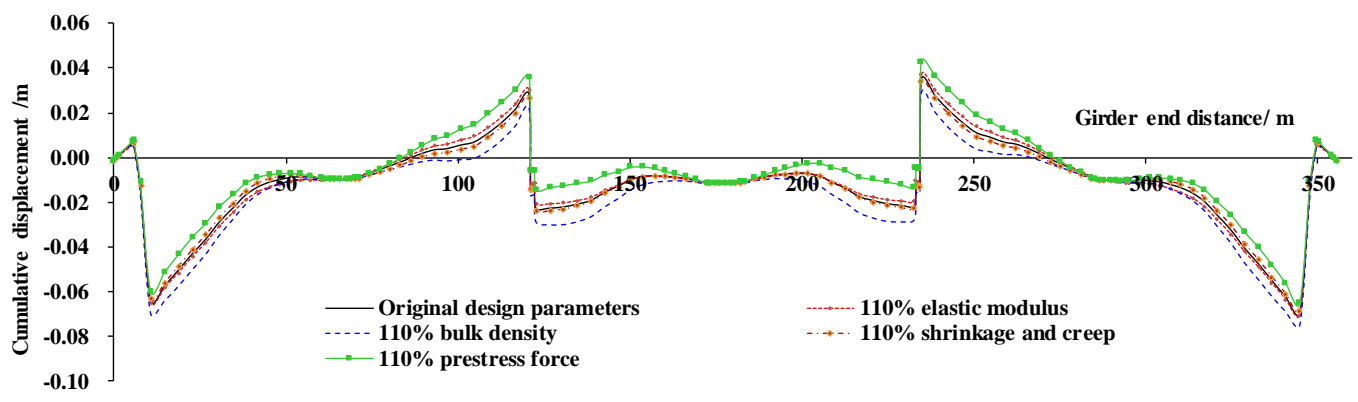

(a) Cumulative vertical displacements of the CRF bridge before and after parameter adjustment

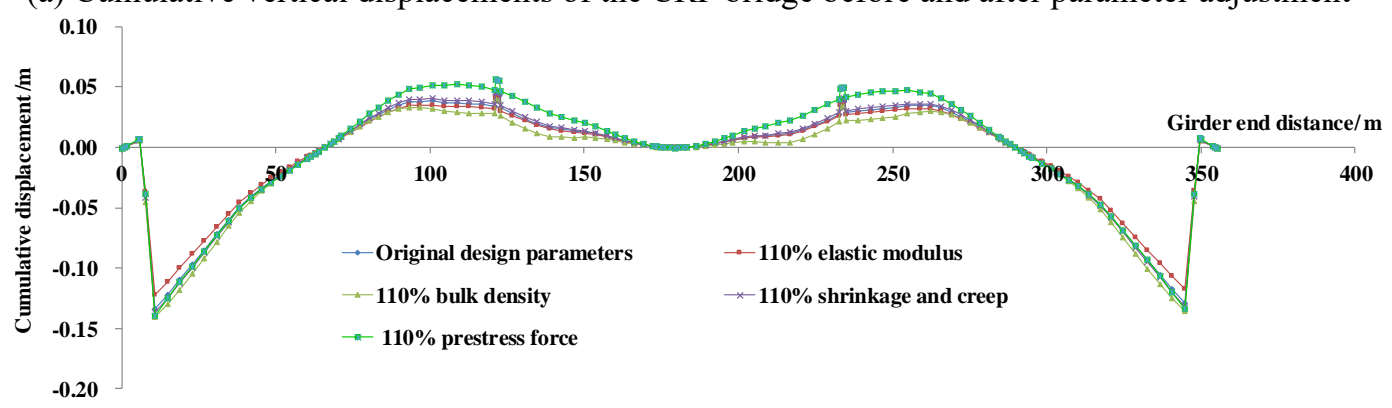

(b) Cumulative vertical displacements of the CG bridge before and after parameter adjustment

Figure 3. Effects of design parameters on cumulative displacement 
As shown in Figure 3, each design parameter affects the cumulative distance of the CRF bridge and that of the CG bridge in different manners.

In the CRF system, the cumulative displacement [16] of the girder generally moved upward with the growth in prestress force. The maximum displacement of the girder suffered from the greatest impact. On the contrary, the cumulative displacement of the girder generally moved downward with the increase of bulk density. The minimum displacement of the girder suffered from the greatest impact. The following can be derived by comparing the situation under the original parameters and that under the adjusted parameters: Despite the parameter adjustment, the cumulative displacement of the CRF bridge follows the original change trend relative to the girder end distance, and changes roughly by the same magnitude $(10 \%)$ as the design parameters; the cross-gap difference in cumulative displacement of the CRF bridge is mainly attributable to the self-weight of unbalanced girder segment [17].

In the CG system, the cumulative displacement of the midspans moved upward, while that of the cantilever end of the side spans moved downward, with the increase in the prestress force. This is because the midspans were closed earlier than the side spans. The effects of the other parameters on the CG system were basically the same with those on the CRF system.

\section{EFFECTS OF PRE-TENSIONING SEQUENCE ON CUMULATIVE DISPLACEMENT}

The pre-tensioning sequence of the closure segment is critical to the construction of the CRF bridge. This section mainly explores the effects of pre-tensioning sequence on the cumulative displacement of the CRF bridge. In the original pre-tensioning plan, the steel cables of the midspans are pretensioned after midspan closure. Without changing the deployment of the steel cables, a new pre-tensioning plan was prepared to pre-tension only $50 \%$ of the steel cables of the midspans after midspan closure. Then, the cumulative displacement of the CRF bridge of the new plan was compared with that of the original plan (Figure 4).

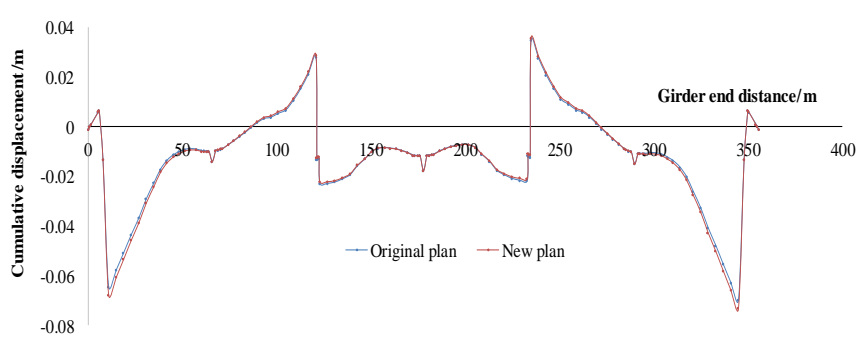

Figure 4. Effects of pre-tensioning plans on cumulative displacement of the CRF bridge

This section also aims to compare the influence of pretensioning sequence on CRF bridge and that on CG bridge. For this purpose, a CG bridge model was created with the same structural dimensions, prestressed steel cables and construction procedures as the superstructure of the four-span CRF bridge. The CG bridge model was also separately pretensioned according to the original plan (pre-tensioning all steel cables of the midspans after midspan closure) and the new plan (pre-tensioning $50 \%$ of the steel cables of the midspans after midspan closure). The cumulative displacement of the CG bridge of the new plan was compared with that of the original plan (Figure 5).

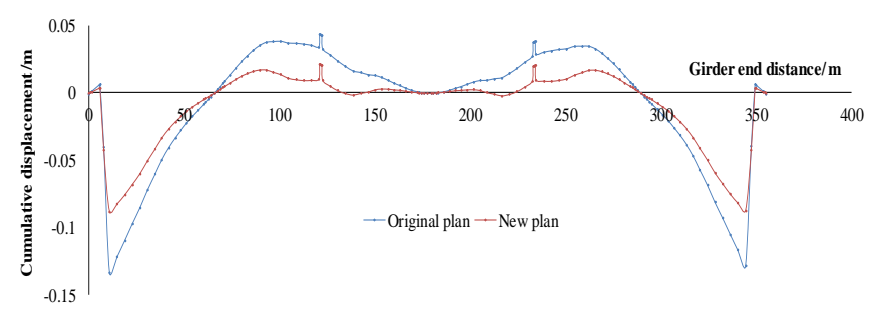

Figure 5. Effects of pre-tensioning plans on cumulative displacement of the $\mathrm{CG}$ bridge

$\begin{array}{llll}\alpha & 1 & 1 & 1\end{array}$

(a)Bending deformation of the girder

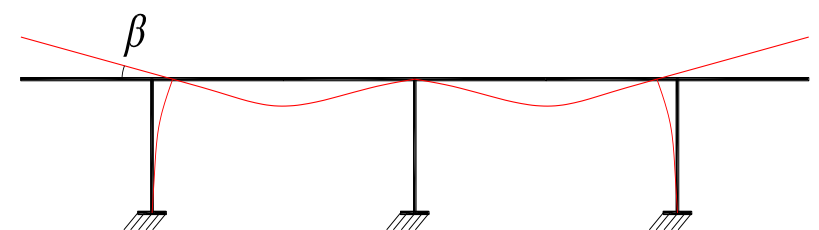

(b)Bending deformation of piers and girder induced by axial force

Figure 6. The deformations induced by the pre-tensioning at the closure segment of the midspans

The following phenomena can be observed from Figures 4 and 5 .

(1) The change of pre-tensioning plan had a slight impact on the CRF bridge. The downward displacements of the side spans increased from $-6.05 \mathrm{~cm}$ in the original plan to $-6.76 \mathrm{~cm}$ in the new plan, and the upward displacements of the midspans underwent extremely small changes.

(2) The change of pre-tensioning plan had a relatively great impact on the CG bridge. The downward displacements of the side spans reduced from $-13.4 \mathrm{~cm}$ in the original plan to -8.84 $\mathrm{cm}$ in the new plan; the upward displacements of the midspans decreased from $4.36 \mathrm{~cm}$ in the original plan to $2.09 \mathrm{~cm}$ in the new plan. Compared with the original plan, the new plan had a low cumulative displacement of the girder structure, and a small cross-gap difference in cumulative displacement. During construction, the cross-gap difference in pre-camber under the new plan was smaller than that under the original plan. Therefore, it is easier to monitor the bridge alignment under the new plan than under the original plan.

(3) The cumulative displacement of the CRF bridge was compared with that of the CG bridge. The comparison shows that the change of pre-tensioning plan only affected the bending moment of the CG bridge, but influenced both the bending moment and shortened the axial length of the girder of the CRF bridge. The reduced axial girder length caused bending deformation of the rigid frame piers. Figure 6 shows the deformations of the CRF bridge and the CG bridge induced by the pre-tensioning at the closure segment of the midspans.

The CG bridge only suffered from the bending deformation of the girder in Figure 5(a). That is why the cumulative 
displacement of the CG bridge changed greatly after the replacement of pre-tensioning plan. By contrast, the CRF bridge was faced with both deformations in Figure 5. Under the two deformations, the displacements were similar in magnitude yet opposite in direction. As a result, the cumulative displacement of the CRF bridge changed slightly after the change of pre-tensioning plan.

\section{EFFECTS OF CLOSURE SEQUENCE ON CUMULATIVE DISPLACEMENT}

Currently, there are two closure sequences for four-span CRF bridges: closing the side spans first (Plan 1) and closing the midspans first (Plan 2). The latter is adopted in the original design plan of the four-span CRF bridge in our study. To reveal the effects of closure sequence on bridge structure, both plans were applied to the CRF bridge model and the CG bridge model with the same superstructure. All the steel cables in a closure segment were all pre-tensioned once that segment was closed. The following can be derived from the results in Figure 7.

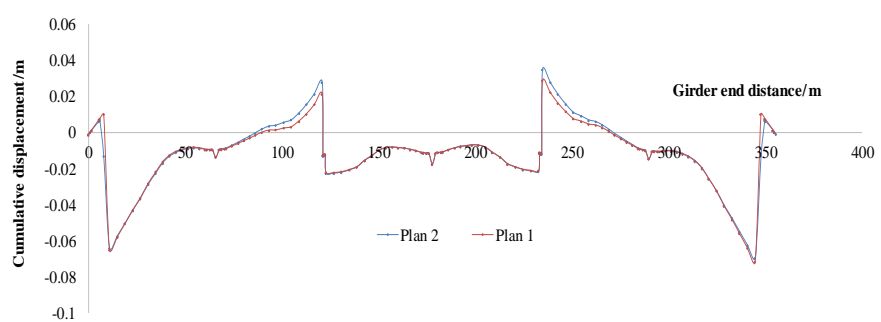

(a) Effects of closure sequence on the cumulative displacement of the CRF bridge

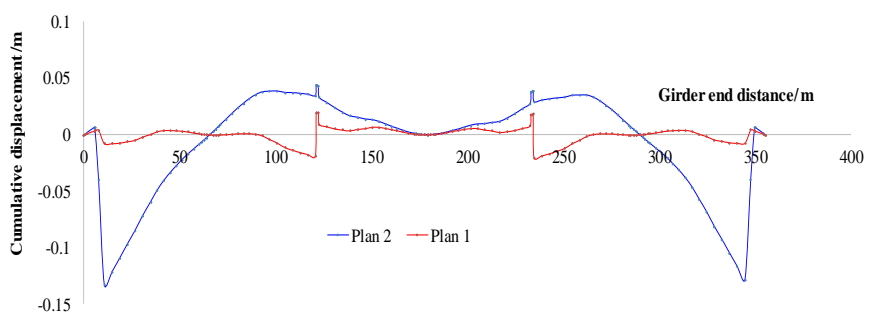

(b) Effects of closure sequence on the cumulative displacement of the CG bridge

Figure 7. Influence of closure sequence on accumulative displacement

(1) The CRF bridge remained largely unchanged in the trend and mean value of deformation, despite the change of closure plan. Thus, the change of closure sequence has limited impacts on CRF bridges.

(2) For the CG bridge, the cumulative displacement and cross-gap difference in cumulative displacement (peak value: $13.95 \mathrm{~cm}$ ) were relatively large in Plan 2 . Hence, it is difficult to monitor the alignment when the midspans are closed first. Under Plan 1, the cumulative displacement and cross-gap difference in cumulative displacement (peak value: $1.3 \mathrm{~cm}$ ) were both small. Therefore, the change of closure sequence has great impacts on CG bridges. If conditions permit, closing the side spans first can greatly facilitate the pre-camber setting and alignment monitoring of CG bridges.

(3) For the CG bridge, all steel cables of the midspans were pre-tensioned after midspan closure under Plan 2. During the pre-tensioning, the structure is a simply-support girder with two cantilevers. In this case, the side span cross-gap difference in cumulative displacement is mainly caused by the bending deformation under the prestress force. Therefore, if the midspans are closed first for the CG system, only part of the steel cables in the midspan closure segment should be pretensioned to reduce the impacts on the side span cross-gap difference in cumulative displacement, without sacrificing the stress and structural safety in the construction process.

\section{CONCLUSIONS}

This paper sets up finite-element models for a CRF bridge and a CG bridge with the same superstructure. With the aid of these models, the author analyzed how design parameters, pretensioning sequence and closure sequence influence the difficulty in alignment monitoring of the CRF structure and the CG structure. The main conclusions are as follows:

(1) Except prestress force, any of the other design parameters has the same impacts on the cumulative displacement of the CRF bridge and that of the CG bridge.

(2) Under the prestress force, the girder deformation of the CRF bridge includes both the bending deformation of the girder and that of the rigid frame girders induced by the shortening of axial girder length. Therefore, the change of pretensioning sequence had limited impacts on girder deformation of CRF bridges.

(3) The change of pre-tensioning sequence has great impacts on CG bridges. If conditions permit, the side spans should be closed first. If the midspans must be closed first, only part of the steel cables in the midspan closure segment should be pre-tensioned, and the other steel cables should be pre-tensioned after the whole bridge is closed, thereby reducing the difficulty in alignment monitoring.

(4) To facilitate alignment monitoring of bridges built with cantilevers, the pre-tensioning and closure sequences should be adjusted in the design phase to minimize the cumulative displacement of the girder and the cross-gap difference in cumulative displacement.

\section{REFERENCE}

[1] Liu, W., Xue, Y.J. (2017). A static load test study for one continuous beam bridge. Environmental and Earth Sciences Research Journal, 4(4): 87-92. https://doi.org/10.18280/eesrj.040401

[2] Xu, L. (2019). Application study on stress optimization design of freeway pc cast-in-situ continuous beam bridge. IOP Conference Series: Earth and Environmental Science, 242(6): 062039. https://doi.org/10.1088/17551315/242/6/062039

[3] Lin, J.R., Zhang, J.P., Zhang, X.Y., Hu, Z.Z. (2019). Automating closed-loop structural safety management for bridge construction through multisource data integration. Advances in Engineering Software, 128: 152-168.

https://doi.org/10.1016/j.advengsoft.2018.11.013

[4] Zou, L.L., Cheng, J.F. (2019). Study on influence of suspension interval length on construction and closure of main girder of continuous rigid frame bridge. IOP Conference Series: Earth and Environmental Science, 295(4): $\quad 042053 . \quad$ https://doi.org/10.1088/1755$1315 / 295 / 4 / 042053$ 
[5] Granata, M.F., Longo, G., Recupero, A., Arici, M. (2018). Construction sequence analysis of long-span cablestayed bridges. Engineering Structures, 174: 267-281. https://doi.org/10.1016/j.engstruct.2018.07.064

[6] Lozano-Galant, J.A., Payá-Zaforteza, I., Xu, D., Turmo, J. (2012). Analysis of the construction process of cablestayed bridges built on temporary supports. Engineering Structures, 40: 95-106. https://doi.org/10.1016/j.engstruct.2012.02.005

[7] Jiang, L.C., Gao, R. (2010). Deformation monitoring during removal of the supporting of T-type rigid frame bridge constructed by rotation method. Procedia Engineering, 4: 355-360. https://doi.org/10.1016/j.proeng.2010.08.041

[8] Dolinajová, K., Moravcík, M. (2013). Monitoring and numerical analysis of construction stages on the bridge realized by the free cantilever method. Procedia Engineering, 65: 321-326. https://doi.org/10.1016/j.proeng.2013.09.049

[9] Jeon, J.C., Lee, H.H. (2019). Development of displacement estimation method of girder bridges using measured strain signal induced by vehicular loads. Engineering Structures, 186: 203-215. https://doi.org/10.1016/j.engstruct.2019.01.107

[10] Erdenebat, D., Waldmann, D., Scherbaum, F., Teferle, N. (2018). The deformation area difference (DAD) method for condition assessment of reinforced structures. Engineering Structures, 155: 315-329. https://doi.org/10.1016/j.engstruct.2017.11.034

[11] Sousa, H., Bento, J., Figueiras, J. (2013). Construction assessment and long-term prediction of prestressed concrete bridges based on monitoring data. Engineering
Structures, 52: 26-37. http://dx.doi.org/10.1016/j.engstruct.2013.02.003

[12] Chacón, R., Zorrilla, R. (2015). Structural health monitoring in incrementally launched steel bridges: Patch loading phenomena modeling. Automation in Construction, 58: 60-73. https://doi.org/10.1016/j.autcon.2015.07.001

[13] Wang, X.Z., Wang, C.Q. (2016). Analysis of temperature stress in control of bridge construction. International Journal of Heat and Technology, 34(4): 715-721. https://doi.org/10.18280/ijht.340423

[14] Xue, Y.J., Liu, W. (2017). Research on application of grey system theory in construction monitoring of continuous rigid frame bridge. Environmental and Earth Sciences Research Journal, 4(4): 93-96. https://doi.org/10.18280/eesrj.040402

[15] Zong, Z.H., Lin, X.S., Niu, J. (2015). Finite element model validation of bridge based on structural health monitoring Part I: Response surface-based finite element model updating. Journal of Traffic and Transportation Engineering, 2(4): 258-278. https://doi.org/10.1016/j.jtte.2015.06.001

[16] Akl, A., Saiid Saiidi, M., Vosooghi, A. (2017). Deflection of in-span hinges in prestressed concrete box girder bridges during construction. Engineering Structures, 131: 293-310. https://doi.org/10.1016/j.engstruct.2016.11.003

[17] Adanur, S., Günaydin, M., Altunişik, A.C., Sevim, B. (2012). Construction stage analysis of humber suspension bridge. Applied Mathematical Modelling, 36(11): https://doi.org/10.1016/j.apm.2012.01.011 